\title{
Long-term survival and diversification of an endemic Melitaea species in mountains of Iran and adjacent areas
}

Article in Journal of Zoological Systematics and Evolutionary Research · May 2016

DOI: $10.1111 / \mathrm{jzs} .12122$

CITATIONS

0

3 authors, including:

\section{János Pál Tóth}

University of Debrecen

20 PUBLICATIONS 65 CITATIONS

SEE PROFILE
READS
Judit Bereczki

University of Debrecen

26 PUBLICATIONS 172 CITATIONS

SEE PROFILE 
1 Long-term survival and diversification of an endemic Melitaea species in

2 mountains of Iran and adjacent areas

3

János P. Tóth ${ }^{1}$, Zoltán Varga ${ }^{2}$, Judit Bereczki ${ }^{1,2}$

5

6

${ }^{1}$ MTA-DE 'Lendület' Behavioural Ecology Research Group, 4032 Debrecen Egyetem tér,

7 Hungary

$8{ }^{2}$ Department of Evolutionary Zoology and Human Biology, Institute of Biology and Ecology,

9

10

11

12 University of Debrecen, 4032 Debrecen Egyetem tér 1, Hungary

Abstract

Disjunct distribution patterns regularly resulted in the separation of different genetic lineages in glacial refugia. Recent patterns of survival and expansion have been often revealed by climatic niche modelling. We used the combination of genetic markers, geometric morphometry and climatic niche modelling to clear up the taxonomy and reconstruct the potential range of an endemic Iranian, taxonomically disputed Melitaea species in climatically different epochs. Our results show that this species (Melitaea abbas Gross \& Ebert, 1975, comb. $n .=$ M. zagrosi Tóth \& Varga syn. nova) is clearly separated from all taxa of the Melitaea phoebe species group and only occurs in Iran and Azerbaijan but was also predicted for some adjacent regions. Molecular markers and distribution modelling show consistently that this species should have had a long-term survival in this area and its range could have been slightly larger during the LGM than currently. Based on the studied molecular markers three main groups in M. abbas can be recognised: those of steppic area of Azerbaijan, Western Iran and North-Eastern Iran. Each group is characterised by own mitochondrial haplotypes, but also a high level of genetic diversity appears in the central part of the distribution area (Zagros Mts.).

Key words: MaxEnt, LGM, Mid-Holocene, geometric morphometry, Bayesian phylogeny

\section{Introduction}

Earth's climate is characterised by series of glacial and interglacial periods. These wellpronounced climatic change events left clear effects on the distribution of animal and plant 
species. According to the most generally accepted contraction-expansion model, temperate species experienced contractions of ranges in glacial periods and expanded their distribution during inter- and postglacial periods (de Lattin 1967; Hewitt 1996). Thus, the majority of these species survived the glacial periods in southern Mediterranean regions such as the Iberian, the Apennine or the Balkan Peninsula. Their disjunct glacial distribution patterns regularly resulted in the separation of different genetic lineages in the three major Mediterranean peninsulas combined with different basic patterns of postglacial expansion referred to as 'paradigms' (Comes and Kadereit 1998; Habel et al. 2005; Hewitt 2000; Hewitt 1999; Taberlet et al. 1998). Although repetitive patterns have been recognised, recent investigations support that the responses of a species might be species-specific (Stewart et al. 2010) and may also depend on life history traits and habitat preference (Bhagwat and Willis 2008).

Additionally, the methodological improvements of the past few decades contribute to the reconsideration of the paradigms. Phylogeography has become an important integrative field of evolutionary biology due to the recent development of molecular analytical tools (Hickerson et al. 2010). Nowadays, the results of molecular analyses such as haplotype networks or phylogenetic inference analysis are often combined with predictions of Species Distribution Models (SDM) to reveal biogeographic dynamics and identify refugial areas (Habel et al. 2011a; Habel et al. 2011b; Schorr et al. 2012; Wielstra et al. 2013). The application of these new techniques reshaped our knowledge on biogeography. For example, recent studies have located numerous extra-Mediterranean refugia, strongly modifying the biogeographical view of Europe. These favourable but geographically limited extraMediterranean areas could have served as refugia during the Last Glacial Maximum even for some Mediterranean species (Varga and Schmitt 2012).

The majority of phylogeographical studies focus on North American and European species. On the contrary, the Middle East is less studied from biogeographical points of view. Few studies have focused on this field, despite that complex landscapes including a number of mountain chains located at the contact zone of the European, Asian and African continents has led to complex phylogenetic relationships between taxa. Moreover, several areas in the Middle East are considered as refugia for several temperate species during climatic oscillations (Gündüz et al. 2007; Gvozdik et al. 2010; Veith et al. 2008; Wielstra et al. 2013). Besides, the application of molecular methods (frequently complemented with modern geometric morphometrics) have considerable effects on taxonomical research, since it often leads to the recognition of cryptic species within putatively well-known taxa such as 
Zerynthia polyxena (Dapporto 2010), Polyommatus icarus (Dinca et al. 2011a) or Leptidea sinapis (Dinca et al. 2011b). Furthermore, it became clear that the traditional view on a given species is based on the misinterpretation of morphological variants as it has been shown in Maculinea rebeli (Bereczki et al. 2005; Fric et al. 2007) some Maniola species (Kreuzinger et al. 2015) or in the case of Melitaea scotosia (Leneveu et al. 2009; Tóth and Varga 2011). The Melitaea phoebe species-group is also a typical example of how improvements of scientific methods modified our view on species boundaries. Using morphological and molecular data, several subspecies of Melitaea phoebe proved to be distinct species such as Melitaea punica (Leneveu et al. 2009; Tóth et al. 2014; Tóth and Varga 2011), Melitaea ornata (Russell et al. 2007; Tóth et al. 2014; Tóth and Varga 2011; Varga et al. 2005) and Melitaea zagrosi (Tóth et al. 2014; Tóth and Varga 2011). Recently, it has also been indicated that M. telona sensu stricto from Israel and M. ornata are different taxa (Tóth et al. 2014). Previous morphometrical studies have already revealed small differences in the genital structures of the males ((Tóth et al. 2013; Tóth and Varga 2011) but the authors interpreted the difference as a well-pronounced intra-specific difference. In contrast, molecular data clearly showed that the two taxa are genetically distinct from each other. Based on the results of the analysis of seven genes, Tóth et al. (2014) concluded that M. telona is not a subspecies of M. ornata but a species in its own right. Melitaea zagrosi Tóth \& Varga, 2011 was described from Iran based on the significant difference in male and female genitalia and the distinct wing pattern. Later, the analysis of DNA reinforced the species level of this taxon. These findings did not allow the synonimisation of M. ornata and M. zagrosi with $M$. telona or each other as suggested by von Oorschot (2014).

The general confusion between these morphologically similar species has prevented the accumulation of biological information. This is especially true in the case of M. zagrosi.

In this study, we provide a wide range of information on Melitaea zagrosi, including of its taxonomy, distribution and phylogeography.

\section{Material and Methods}

\section{Sample material}

The samples were obtained from the Hungarian Natural History Museum, the Zoological State Collection of Munich, Staatliches Museum für Naturkunde, Karlsruhe, the collection of Jagellonian University of Krakow and the Lepidoptera collection of University of Debrecen. 
103 DNA was extracted from the head or the proximal end of the abdomen following the protocol in Bereczki et al. (2014) from 30 specimens (Table 1.). The cytochrome c oxidase subunit I gene (COI), which is commonly used in barcoding animal life (Hebert et al., 2003; Wiemers \& Fiedler, 2007), offers an adequate tool to obtain insight into the phylogeny of taxa at species level. We therefore sequenced this section of the mitochondrial genome together with the nuclear elongation factor $1 \quad(E F-1)$, malate dehydrogenase $(M D H)$, ribosomal protein $\mathrm{S} 5$ $(R p S 5)$ and wingless $(w g)$. These genes were amplified by specific primers modified at their 5 '-end to include the universal sequencing primer T7 promoter (Wahlberg \& Wheat, 2008). Amplification from $1 \mu \mathrm{l}$ of DNA extracts was carried out in $25 \mu 1$ final reaction volumes containing $5 \times$ PCR buffer, $2 \mathrm{mM} \mathrm{MgCl}, 0.2 \mathrm{mM}$ dNTPs, 0.02 units/ $\mu 1$ of Taq DNA polymerase (Phusion Hot Start II High-Fidelity, Thermo Scientific) and $0.3 \mu \mathrm{M}$ of each primer. Amplification was carried out in an ABI Veriti thermal cycler programmed for: initial denaturation for $3 \mathrm{~min}$ at $94^{\circ} \mathrm{C} ; 35$ cycles of $30 \mathrm{~s}$ at $94 \mathrm{C}, 30 \mathrm{~s}$ at the locus specific annealing temperature, $1 \mathrm{~min}$ at $72 \mathrm{C}$; final elongation of $10 \mathrm{~min}$ at $72 \mathrm{C}$. The success of PCR amplification was checked by running $2 \mu \mathrm{L}$ of product on $1 \%$ agarose gels stained with GelRed Nucleic Acid Stain (Biotium Inc.). PCR-products were sequenced by commercial service provider Macrogen Inc. (Seoul, South Korea).

Although COI proved to be highly informative in phylogenetic and phylogeographic studies and most of the cases it is suitable for species identification, recently it became clear that it could be manipulated by the intracellular bacteria genus Wolbachia. This microorganism could induce 'two barcodes - one species' (Kodandaramaiah et al. 2013) or its opposite, 'one barcode - two species' phenomenon (Jiggins 2003). In these cases, the results of mitochondrial DNA based analyses could be misleading. Thus, a phylogeographic or a phylogenetic study is inconceivable without the screening of Wolbachia presence in the sample material. The presence of Wolbachia was checked by polymerase chain reaction (PCR) by the amplification of the highly conservative 16S ribosomal RNA gene with Wolbachia specific primers W-Spec of Werren and Windsor (2000), following the protocols described by these authors. The success of PCR amplification was checked by running $2 \mu 1$ of product on $1 \%$ agarose gels.

DNA sequences were edited and revised manually by Chromas Lite v. 2.01, then aligned using MEGA v. 6 (Tamura et al., 2011). For statistical analysis of the aligned datasets Bayesian analyses was conducted using MrBayes 3.2.5 (Ronquist et al., 2012) on single-gene, nuclear genes only and all-gene datasets. The multiple genes datasets were partitioned by 
genes. The different models of molecular evolution were sampled for each gene (both single and combined data) and the model-jumping feature was used through the command 'lset applyto $=$ (all) nucmodel $=4$ by 4 nst $=$ mixed rates $=$ gamma covarion $=$ no;'

Two independent MCMC runs each with four simultaneous chains (one cold and three heated) for each analysis were run for 10 million generations and the sampling of trees and parameters was set to every 1000 generations. Convergence of the two runs was determined by the stationary distribution plot of the log-likelihood values against number of generations and confirmed by the average standard deviation of split frequencies which were lower than 0.05 in all cases. We discarded the first 2500000 generations as burn-in and trees were summarized under the $50 \%$ majority rule method. The summarised tree with posterior probabilities were plotted using FigTree (http://tree.bio.ed.ac.uk/software/figtree/)

Additionally, a haplotype network was constructed using the R computing environment (RCoreTeam, 2014) with pegas package v. 0.81 (Paradis, 2010). For haplotype analysis we used COI sequences without ambiguities. Haplotypes distribution in geographical space was visualised using QGIS (QGIS Development Team, 2015).

\section{Morphometry}

Geometric morphometry was used to determine morphological relationships among Melitaea phoebe, M. ornata, M. zagrosi and some paratypes of M. phoebe abbas Gross \& Ebert, 1975 (described from South-Iran, Fars province, $50 \mathrm{~km} \mathrm{NW}$ Ardekan Tange Surkh, 2250m). In total, 107 specimens have been measured. The analysed material is partly identical with the specimens used in Tóth \& Varga (2011) but it has been completed with a significant amount of new material (Appendix Table 1).

We analysed the shape of the processus posterior (male genitalia) which has already proved to be useful in the Melitaea phoebe species group. We followed a standard genital preparation method. The abdomens were removed and heated in $15 \% \mathrm{KOH}$ solution in $80 \mathrm{C}^{\circ}$ for 30 minutes. Next, genitalia were cleaned and dehydrated in ethanol and mounted in euparal. Genitalia slides were digitalized using a combination of a stereo microscope and a digital camera.

TpsDig2 was used to record 9 landmarks at the tips and origin of the main processi (Fig. 1) similarly to Tóth \& Varga (2011). The raw coordinates were transformed using Procrustes Generalised Least Squares. Based on the transformed coordinates we used Canonical Variance Analysis (CVA) to determine the morphological relationships between the studied taxa. We visually inspected the shape changes along the axes using landmark warp function. 
Jack-knife grouping was also used to quantify the classification success. In Jack-knife, specimens are alternately excluded for each run and assigned using the CVA axes. The significance of the visible pattern was analysed by pair-wise MANOVA using Bonferroni corrected significance levels. All the morphometrical analyses were carried out by PAST 2.17 (Hammer et al. 2001).

Although DNA analysis indicated that none of our Iranian specimens belongs to Melitaea ornata, all of them turned out to represent Melitaea zagrosi including the North Eastern Iranian samples from the Eastern Elburs and the Kopeth-Dagh. At the same time, a previous morphometrical study (Tóth \&Varga 2011) showed that $M$. ornata also occurs in the KopethDagh Mountain range., Most of these specimens are unfortunately worn, thus we were not able to detect the identification traits described in Tóth \& Varga 2011. Therefore, the specimens from North-Eastern Iran were classified as ungrouped cases even if additional information was available based on DNA (ZAIR16, ZAIR18) or based on the well-preserved wing colouration pattern (P111, P103).

\section{$S D M$}

The MaxEnt modelling method was used to predict the potential distribution of Melitaea zagrosi using BIOCLIM variables (Busby 1991). Among a broad variety of distribution modelling tools, MaxEnt is one of the most commonly used method for predicting species distributions and environmental tolerances using presence-only data (Warren and Seifert 2010). MaxEnt's predictive performance is consistently competitive with the highest performing methods (Elith et al. 2011), moreover MaxEnt shows little sensitivity to small sample sizes (Sinclair et al. 2010). Based on the examined specimens in this article we could use 17 non-overlapping presence points for modelling (Fig. 4). The climate variables were downloaded from WoldClim database (www.worldclim.com).

Although MaxEnt is more robust in controlling for correlations between variables than stepwise regression (Elith et al. 2011), strongly correlated variables ( $r>0.75)$ recommended to excluded from the analysis (see: Elith et al. 2010, Stohlgren et al. 2010). ENMtools 1.3 was used to calculate the level of correlations (Warren \& Seifert 2010). To assess which predictors provide the most useful information by itself we applied jackknife test using MaxEnt. Since the biology of $M$. zagrosi is basically unknown, the results of jackknife and the correlation tests were considered during variable selection. Finally, four variables were selected: bio11 (mean temperature of coldest quarter), bio18 (precipitation of warmest quarter), bio4 (temperature seasonality) and bio15 (precipitation seasonality). 
The discrimination ability of the model was evaluated by Area Under the Curve (AUC) metric. The value of AUC ranges between 0.0 and 1.0 where 1.0 is considered perfect prediction and for values $<=0.5$ prediction is considered not significantly deviating from random distribution (Fielding \& Bell 1997, Franklin 2009).

The results were visualised on a logarithmic scale, where MaxEnt provides an estimate ranging between 0 and 1 as a metric of climatic suitability for the species.

The distribution model was also projected to the Mid-Holocene climate optimum (MH), i.e. $\sim 6000$ years before present (yBP) and the Last Glacial Maximum (LGM), i.e. 21000 years before present (yBP). For the projections we used the predictions of two different global circulation models (MIROC and CCSM).

\section{Results}

\section{$D N A$}

In total, 30 specimens were sequenced for five genes (a mitochondrial and four nuclear genes) (Table 1). The final concatenated sequences involved 3818 base pairs (bp), of which $1414 \mathrm{bp}$ were from COI and $2404 \mathrm{bp}$ from the nuclear regions. None of the specimens were infected with Wolbachia. The consensus phylogeny from the Bayesian inference analysis clearly separated the species. The sequenced specimens from Iran clustered with Melitaea zagrosi except for the single M. phoebe specimen (PHIR) which was well-separated (Fig. 2). Based on the combined gene phylogram, three main groups of $M$. zagrosi were identified: those belonging to steppic area of Azerbaijan, Western Iran and North-Eastern Iran. In total, 9 unique haplotypes were identified based on 1414 bp COI sequences which contained 17 parsimony informative sites. The COI-based unique haplotypes were plotted as a network and additionally as geo-referenced pie charts. The distribution of the haplotypes shows a strong geographic pattern. Similarly to the combined gene analysis, the distribution of the haplotypes indicates the separation of the three geographical regions: the steppic area of Azerbaijan, Western Iran and the North-Eastern Iran which all exhibited unique haplotypes (see in Electronic Appendix Fig. 1).

\section{Morphometry}

The shape of the processus posterior of the studied Melitaea species was significantly different with high discriminatory power (Wilks $\lambda=0.05, \mathrm{p}<0.001$ ). The first axis explained $79 \%$ while the second $17 \%$ of variance between groups. On the CVA plot M. ornata and $M$. 
phoebe are slightly overlapping while the M. zagrosi is well-separated from the other two species (Fig. 3). The paratypes of M. phoebe abbas that were set as one of our apriori groups were mixed together with $M$. zagrosi specimens. The pairwise MANOVA with Bonferroni corrected significance levels showed the same pattern. All the apriori groups were significantly different ( $\mathrm{p}<0.001)$ with the exception of 'abbas' and 'zagrosi' (Table 2 ).

The jackknifed classification assigned $77.5 \%$ of the individuals correctly. Most of the misclassifications occurred between abbas and zagrosi. Besides, few misclassifications could be found between ornata and phoebe (Table 3).

The ungrouped specimens from North-Eastern Iran were classified into the zagrosi and ornata groups. It is remarkable that the two specimens which were also sequenced (ZAIR16, ZAIR18) were classified into zagrosi. Interestingly, the two specimens from the same locality (Transkaspian region, Arwas) were classified into different groups and one of the specimens was positioned between ornata and zagrosi (B66) which is proved to be zagrosi based on mtDNA.

\section{Distribution modelling}

Despite the low number of presence data, the MaxEnt's prediction for current climatic conditions seems to be realistic. It is remarkable that the model predicted a very small suitable area in Azerbaijan located only in the southern mountainous region and not in steppic areas, although specimens were available from that region. In addition to Iran, relatively large suitable areas were predicted within Turkey, Turkmenistan and Afghanistan (Fig. 4).

Model projections fitted to the Last Glacial Maximum suggest relatively small area fluctuations. The two circulation models predicted very similar environments for this period. The predictions of both models (CCSM, MIROC) showed larger potential distribution of the species in the steppic area of Azerbaijan. The prediction for the Mid-Holocene showed a slightly smaller potential area.

The predictions of MaxEnt for different time scales show that the species was able to survive the recent climate fluctuations in the mountainous regions of Iran.

\section{Discussion}

In this study we provide a wide range of information on the recently described taxa $M$. zagrosi based on the analysis of five genes, geometric morphometrics and distribution modelling. The shape of the processus posterior proved to be a useful character to separate M. zagrosi from M. phoebe or M. ornata. The results of genitalia morphometry are generally in agreement 
with the five-gene-based phylogeny reconstruction. Concerning morphometry, we obtained the same results as provided by Tóth \& Varga (2011). It also became clear that genitalia morphology is a more reliable character than wing colouration in those cases when the specimen is worn or lost its typical colouration due to long-time storage. The jackknife classification results show that Melitaea zagrosi can be identifiable in nearly $100 \%$ based on the male genitalia.

Our findings based on four nuclear (EF-1a, MDH, RpS5 and wg) and a single mitochondrial (COI) genes support that differences in the shape of the processus posteriores qualify for species-level differences. The strong correlations between genitalia morphometry and the results of DNA analyses allow us to draw conclusions based on morphometry. This is crucial for this study since we failed to amplify genes from the type material due to the age of the specimens.

We examined the male genitalia of the type material of $M$. phoebe abbas. The CVA was not able to separate the paratypes of $M$. phoebe abbas from $M$. zagrosi but it clearly separated the taxa from $M$. phoebe and M. ornata. Therefore, the taxa Melitaea phoebe abbas Gross \& Ebert, 1975 is neither a subspecies of Melitaea phoebe nor of Melitaea ornata, but conspecific with the recently described Melitaea zagrosi Tóth \& Varga, 2011. Thus, in concordance with the rule of the priority Melitaea zagrosi Tóth \& Varga, 2011 is a junior subjective synonym of Melitaea abbas Gross \& Ebert, 1975, comb. $n$. Henceforth, we use the valid name of the species.

It is remarkable that all the sequenced specimens from Iran were identified as M. abbas or $M$. phoebe and none of them belongs to M. ornata. It seems that the distribution of Melitaea ornata is very limited in Iran. Probably it occurs only in Northern Iran: in certain parts of the Kopeth-Dagh Mountains and the adjacent areas in Turkmenistan. However, further studies are necessary to clarify this question. The results of MaxEnt modelling suggest that M. abbas has a relatively narrow ecological tolerance. The predicted potential distribution is restricted to a relatively small geographical area. The known present distribution is located in Iran and adjacent areas. All the Iranian populations were typically found in the forest-steppic biotopes of Iran. Generally, the occurrences of M. abbas show an interesting co-incidence with two different semi-open vegetation formations: Pistacia-Amygdalus forest-steppe and Quercus brantii forest-steppe in Western Iran (mostly in Zagros Mts.) and Juniperus forest-steppe in the Northern and North-Eastern regions of the country (mainly in Elburs and Kopeth-Dagh Mts.) (Djamali 2008). Therefore, M. abbas is increasing the number of narrowly distributed 
endemic Melitaea species in the Middle East (e.g. M. turkmanica, M. collina, M. sarvistana, M. tangighaurensis, M. interrupta, M. persea).

Interestingly, most of the species belonging to the phoebe-group are adapted to dry and warm climatic conditions. These species occupy clearly separated areas. M. punica is only found in North-Western Africa. The situation is very similar in the case of $M$. telona which is distributed exclusively in the Levant region. M. abbas is only distributed in Iran and adjacent areas. Molecular results imply that $M$ ornata, which can be characterised by a relatively large range, does not occur or only rarely in these areas. In contrast, $M$. abbas is unknown from Turkey where M. ornata is widely distributed (Hesselbarth et al. 1995; Tóth and Varga 2011). All three species, M. ornata, M. telona and M. abbas are strictly monovoltine with larval aestivation in the hottest and driest periods of the summer. Thus, they are predicted to have similar adaptation mechanisms to prevent the damages due to extreme temperatures and aridity. Correspondingly, we found that caterpillars' nests of $M$. ornata in forest-steppic habitats in Hungary are located in semi-shadowed spots of the habitat. Thus, the survey for ecological constraints in the life-cycle of $M$. abbas would be a fascinating task for the future.

Paleoclimatic predictions showed that suitable areas for the species continuously existed during the Last Glacial Maximum and Mid-Holocene. Based on recent results of Species Distribution Modelling and also molecular results, several mountain ranges (e.g. Elburz, Zagros, Kopeth-Dagh) in Iran have already been considered as refugia during climatic oscillations (Ahmadzadeh et al. 2013; Gvozdik et al. 2010; Rajaei et al. 2013). These results suggest that $M$. abbas was not able to significantly expand its distribution. This phenomenon could be explained by various hypotheses. It is possible that the species is strongly limited by certain environmental conditions as well as strict food plant specialisation. These factors could strongly limit the distribution of a species (Hanspach et al. 2014; Wisz et al. 2013).

The molecular analysis found three well separated groups in M. abbas which are localised in three different regions (Azerbaijan, Western Iran including Zagros Mts. and North-Eastern Iran, mostly Khorasan region). All of these areas were characterised by unique haplotypes. According to the consensus phylogeny based on five genes, clear diversification was shown between the specimens from the steppic areas of Azerbaijan and the rest of the sequenced $M$. abbas material. Unfortunately, we only had few specimens from this region thus detailed morphometrical analysis was not possible but this could be an interesting aim for the future research.

The result of distribution modelling indirectly indicated that the populations in Azerbaijan occur in a different climatic regime than in Iran, since MaxEnt did not predict suitable climate 
for the steppic areas of Azerbaijan. Although this pattern is obviously the result of the fact that we had only one presence point from this area, it clearly indicates climatic isolation. The adaptation to steppic conditions could lead to pronounced genetic differentiation of these populations.

The other two groups showed more close genetic relation to each other based on the combined gene analysis. The specimens from Western Iran (Zagros Mts., Talysh Mts. and Western part of Elburs Mts.) could be considered as another unit which shows close relationships with the North-Eastern-Iranian group (Kopeth-Dagh, Eastern Elburs). Besides, the COI-based haplotype network separates the previously described three groups although it shows different relatedness. The genetic diversity of the Zagros Mountains is remarkable which could be the outcome of the long-time survival of the species in this region. It would not be right to make conclusions on the other two groups' genetic diversity since only few specimens were analysed in comparison to the Western-Iranian group.

352 In summary, our results confirmed the previous studies demonstrating the taxonomic distinctness of M. abbas from the other Melitaea species. Moreover, three well-separated lineages were identified applying molecular markers which are also supported by the results of species distribution modelling methods. This study also highlights the biogeographical importance of the Middle East since this region provided an opportunity of long-term survival for different organisms such as M. abbas which demonstrates essentially different area dynamics as compared to most European species.

\section{Acknowledgement}

We are very grateful to Dr. Bálint Zsolt (Hungarian Natural History Museum), Dr. Axel Hausmann, Ulf Buchsbaum (Zoologische Staatssammlung, München) and Dr. Tomasz W. Pyrcz (Zoological Museum of the Jagellonian University, Krakow) for the valuable museum specimens. We also thanks for Hossein Rajei who made one genital slide from one specimen of the paratypes of $M$. phoebe abbas and Dr. Robert Trusch, Michael Falkenberg, Günter Ebert (Staatliches Museum für Naturkunde, Karlsruhe) for four specimens of the paratypes of M. phoebe abbas. We also have to thank Valentin V. Tikhonov for the specimens from Azerbaijan and Zsolt Végvári for the linguistic corrections. K84071). JB was supported by János Bolyai Scholarship of the Hungarian Academy of 


\section{References}

375

Ahmadzadeh F, Carretero MA, Rödder D, Harris DJ, Freitas SN, Perera A, Böhme W (2013) Inferring the effects of past climate fluctuations on the distribution pattern of Iranolacerta (Reptilia, Lacertidae): Evidence from mitochondrial DNA and species distribution models. Zoologischer Anzeiger - A Journal of Comparative Zoology 252:141-148.

Bereczki J, Pecsenye K, Peregovits L, Varga Z (2005) Pattern of genetic differentiation in the 382 Maculinea alcon species group (Lepidoptera, Lycaenidae) in Central Europe. Journal of Zoological Systematics and Evolutionary Research 43:157-165.

Bhagwat SA, Willis KJ (2008) Species persistence in northerly glacial refugia of Europe: a 385 matter of chance or biogeographical traits? Journal of Biogeography 35:464-482.

Busby JR (1991) BIOCLIM: a bioclimate analysis and prediction system. Plant protection quarterly 6:8-9.

Comes HP, Kadereit JW (1998) The effect of Quaternary climatic changes on plant 389

Dapporto L (2010) Speciation in Mediterranean refugia and post-glacial expansion of Zerynthia polyxena (Lepidoptera, Papilionidae). Journal of Zoological Systematics and Evolutionary Research 48:229 - 237.

de Lattin G (1967) Grunddriß der Zoogeographie. Gustav Fischer Verlag, Jena.

Dinca V, Dapporto L, Vila R (2011a) A combined genetic-morphometric analysis unravels the complex biogeographical history of Polyommatus icarus and Polyommatus celina Common Blue butterflies. Molecular Ecology 20:3921-3935.

Dinca V, Lukhtanov VA, Talavera G, Vila R (2011b) Unexpected layers of cryptic diversity in wood white Leptidea butterflies. Nat Commun 2.

Djamali M (2008) Palaeoenvironmental changes in Iran during the last two climatic cycles (vegetation-climate-anthropisation). Science and Technology Division, Aix-Marseille University, Marseille.

Elith J, Phillips SJ, Hastie T, Dudík M, Chee YE, Yates CJ (2011) A statistical explanation of MaxEnt for ecologists. Diversity and Distributions 17:43-57.

Fric Z, Wahlberg N, Pech P, Zrzavy J (2007) Phylogeny and classification of the PhengarisMaculinea clade (Lepidoptera: Lycaenidae): total evidence and phylogenetic species concepts. Systematic Entomology 32:558-567. 
Gündüz İ, Jaarola M, Tez C, Yeniyurt C, Polly PD, Searle JB (2007) Multigenic and morphometric differentiation of ground squirrels (Spermophilus, Scuiridae, Rodentia) in Turkey, with a description of a new species. Molecular Phylogenetics and Evolution 43:916-935.

Gvozdik V, Moravec J, Klütsch C, Kotlik P (2010) Phylogeography of the Middle Eastern tree frogs (Hyla, Hylidae, Amphibia) as inferred from nuclear and mitochondrial DNA variation, with a description of a new species. Molecular Phylogenetics and Evolution 55:1146-1166.

Habel J, Lens L, Rödder D, Schmitt T (2011a) From Africa to Europe and back: refugia and range shifts cause high genetic differentiation in the Marbled White butterfly Melanargia galathea. BMC Evolutionary Biology 11:215.

Habel JC, Husemann M, RÖDder D, Schmitt T (2011b) Biogeographical dynamics of the Spanish Marbled White Melanargia ines (Lepidoptera: Satyridae) in the Western Mediterranean: does the Atlanto-Mediterranean refuge exist? Biological Journal of the Linnean Society 104:828-837.

Habel JC, Schmitt T, Müller P (2005) The fourth paradigm pattern of post-glacial range expansion of European terrestrial species: the phylogeography of the Marbled White butterfly (Satyrinae, Lepidoptera). Journal of Biogeography 32:1489-1497.

Hammer Ø, Harper DAT, Ryan PD (2001) PAST: Paleontological Statistics Software Package for education and data analysis. Palaeontologia Electronica 4:1-9.

Hanspach J, Schweiger O, Kühn I, Plattner M, Pearman PB, Zimmermann NE, Settele J (2014) Host plant availability potentially limits butterfly distributions under cold environmental conditions. Ecography 37:301-308.

Hebert PDN, Ratnasingham S, de Waard JR (2003) Barcoding animal life: cytochrome c oxidase subunit 1 divergences among closely related species. Proceedings of the Royal Society of London. Series B: Biological Sciences, 270:S96-S99.

Hesselbarth G, Oorschot HV, Wagener S (1995) Die Tagfalter der Turkei unter Berücksichtigung der angrenzenden Länder: (Lepidoptera Papilionoidea and Hesperioidea) Goecke \& Evers, Bochold.

Hewitt G (2000) The genetic legacy of the Quaternary ice ages. Nature 405:907-913.

Hewitt GM (1996) Some genetic consequences of ice ages, and their role in divergence and speciation. Biological Journal of the Linnean Society 58:247-276.

Hewitt GM (1999) Post-glacial re-colonization of European biota. Biological Journal of the Linnean Society 68:87-112. 
Hickerson MJ, Carstens BC, Cavender-Bares J, Crandall KA, Graham CH, Johnson JB, Rissler L, Victoriano PF, Yoder AD (2010) Phylogeography's past, present, and future: 10 years after Avise, 2000. Molecular Phylogenetics and Evolution 54:291301.

Jiggins FM (2003) Male-killing Wolbachia and mitochondrial DNA: selective sweeps, hybrid introgression and parasite population dynamics. Genetics, 164:5-12.

Kodandaramaiah U, Simonsen TJ, Bromilow S, Wahlberg N, Sperling F (2013) Deceptive single-locus taxonomy and phylogeography: Wolbachia-associated divergence in mitochondrial DNA is not reflected in morphology and nuclear markers in a butterfly species. Ecology and Evolution, 3:5167-5176.

Kreuzinger AJ, Fiedler K, Letsch H, Grill A (2015) Tracing the radiation of Maniola (Nymphalidae) butterflies: new insights from phylogeography hint at one single incompletely differentiated species complex. Ecology and Evolution 5:46-58.

Leneveu J, Chichvarkhin A, Wahlberg N (2009) Varying rates of diversification in the genus Melitaea (Lepidoptera: Nymphalidae) during the past 20 million years. Biological Journal of the Linnean Society 97:346-361.

Paradis E (2010) PEGAS: an R package for population genetics with an integrated-modular approach. Bioinformatics, 26:419-420.

QGIS Development Team (2015) QGIS Geographic Information System. Open Source Geospatial Foundation Project.

Rajaei H, Rödder D, Weigand AM, Dambach J, Raupach MJ, Wägele JW (2013) Quaternary refugia in southwestern Iran: insights from two sympatric moth species (Insecta, Lepidoptera). Organism Diversity \& Evololution 13:409-423.

R-CoreTeam (2014) R: A Language and Environment for Statistical Computing. R Foundation for Statistical Computing, Vienna, Austria.

Ronquist F, Teslenko M, van der Mark P, et al. (2012) MrBayes 3.2: efficient bayesian phylogenetic inference and model choice across a large model space. Systematic Biology, 61:539-542.

Russell P, Tennent WJ, Pateman J, Varga Z, Benyamini D, Pe'er G, Bálint Z, Gascoigne-Pees M (2007) Further investigations into Melitaea telona Frushstorfer, 1908 (=ogygia Frushstorfer, 1908 =emipunica Verity, 1919) (Lepidoptera: Nymphalidae), with observations on biology and distribution. Entomologist's Gazette 58:137-166. 
Schorr G, Holstein N, Pearman PB, Guisan A, Kadereit JW (2012) Integrating species distribution models (SDMs) and phylogeography for two species of Alpine Primula. Ecology and Evolution 2:1260-1277.

Sinclair SJ, White MD, Newell GR (2010) How useful are species distribution models for managing biodiversity under future climates? Ecology and Society 15:8.

Stewart JR, Lister AM, Barnes I, Dalén L (2010) Refugia revisited: individualistic responses of species in space and time. Proceedings of the Royal Society B: Biological Sciences 277:661-671.

Stohlgren TJ, Ma P, Kumar S, Rocca M, Morisette JT, Jarnevich CS, Benson N (2010) Ensemble Habitat Mapping of Invasive Plant Species. Risk Analysis 30:224-235.

Taberlet P, Fumagalli L, Wust-Saucy A-G, Cosson J-F (1998) Comparative phylogeography and postglacial colonization routes in Europe. Molecular Ecology 7:453-464.

Tamura K, Peterson D, Peterson N, Stecher G, Nei M, Kumar S (2011) MEGA5: Molecular evolutionary genetics analysis using maximum likelihood, evolutionary distance, and maximum parsimony methods. Molecular Biology and Evolution, 28:2731-2739.

Tóth JP, Bereczki J, Varga Z, Rota J, Sramkó G, Wahlberg N (2014) Relationships within the Melitaea phoebe species group (Lepidoptera: Nymphalidae): new insights from molecular and morphometric information. Systematic Entomology 39:749-757.

Tóth JP, Varga K, Végvári Z, Varga Z (2013) Distribution of the Eastern knapweed fritillary (Melitaea ornata Christoph, 1893) (Lepidoptera: Nymphalidae): past, present and future. Journal of Insect Conservation 17:245-255.

Tóth JP, Varga Z (2011) Inter- and intraspecific variation in the genitalia of the 'Melitaea phoebe group' (Lepidoptera, Nymphalidae). Zoologischer Anzeiger - A Journal of Comparative Zoology 250:258-268.

van Oorschot H, Coutsis JG (2014) The genus Melitaea Fabricius, 1807. Taxonomy and systematics with special reference to the male genitalia (Lepidoptera, Nymphalidae, Nymphalinae). Tshikolovets, Pardubice.

Varga Z, Schmitt T (2012) Extra-Mediterranean refugia: The rule and not the exception? Frontiers in Zoology 9:1-12.

Varga Z, Szabó S, Kozma P (2005) Melitaea ogygia kovacsi Varga, 1967 (Lepidoptera, Nymphalidae) in the Pannonian region: taxonomy, bionomy, conservation biology. In: Kühn E, Feldmann, R, Thomas, J. \& Settele, J. ed., Studies on the Ecology and Conservation of butterflies in Europe. UFZ Leipzig-Halle, pp. 65-68. 
Veith M, Lipscher E, Öz M, Kiefer A, Baran I, Polymeni RM, Steinfartz S (2008) Cracking the nut: Geographical adjacency of sister taxa supports vicariance in a polytomic salamander clade in the absence of node support. Molecular Phylogenetics and Evolution 47:916-931.

Warren DL, Seifert SN (2010) Ecological niche modeling in Maxent: the importance of model complexity and the performance of model selection criteria. Ecological Applications 21:335-342.

Werren JH, Windsor DM (2000) Wolbachia infection frequencies in insects: evidence of a global equilibrium? Proceedings of the Royal Society B: Biological Sciences 267:1277-1285.

Wielstra B, Crnobrnja-Isailović J, Litvinchuk SN, Reijnen BT, Skidmore AK, Sotiropoulos K, Toxopeus AG, Tzankov N, Vukov T, Arntzen JW (2013) Tracing glacial refugia of Triturus newts based on mitochondrial DNA phylogeography and species distribution modeling. Frontiers in Zoology 10:13-13.

Wiemers M, Fiedler K (2007) Does the DNA barcoding gap exist? - a case study in blue butterflies (Lepidoptera: Lycaenidae). Frontiers in Zoology, 4:8.

Wisz MS, Pottier J, Kissling WD, Pellissier L, Lenoir J, Damgaard CF, Dormann CF, Forchhammer MC, Grytnes J-A, Guisan A, Heikkinen RK, Høye TT, Kühn I, Luoto M, Maiorano L, Nilsson M-C, Normand S, Öckinger E, Schmidt NM, Termansen M, Timmermann A, Wardle DA, Aastrup P, Svenning J-C (2013) The role of biotic interactions in shaping distributions and realised assemblages of species: implications for species distribution modelling. Biological Reviews 88:15-30.

\section{Figures}

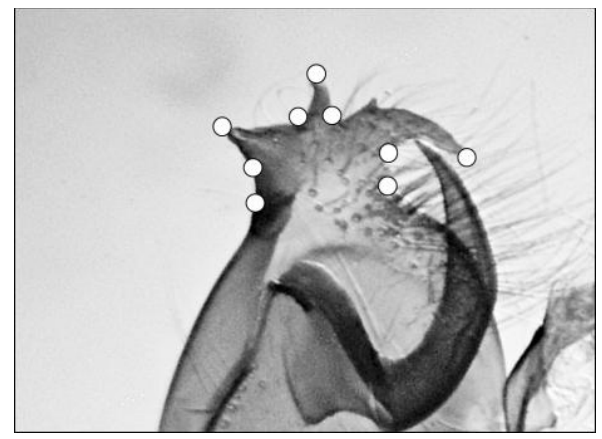

Fig. 1. Landmarks on the processus posterior. 


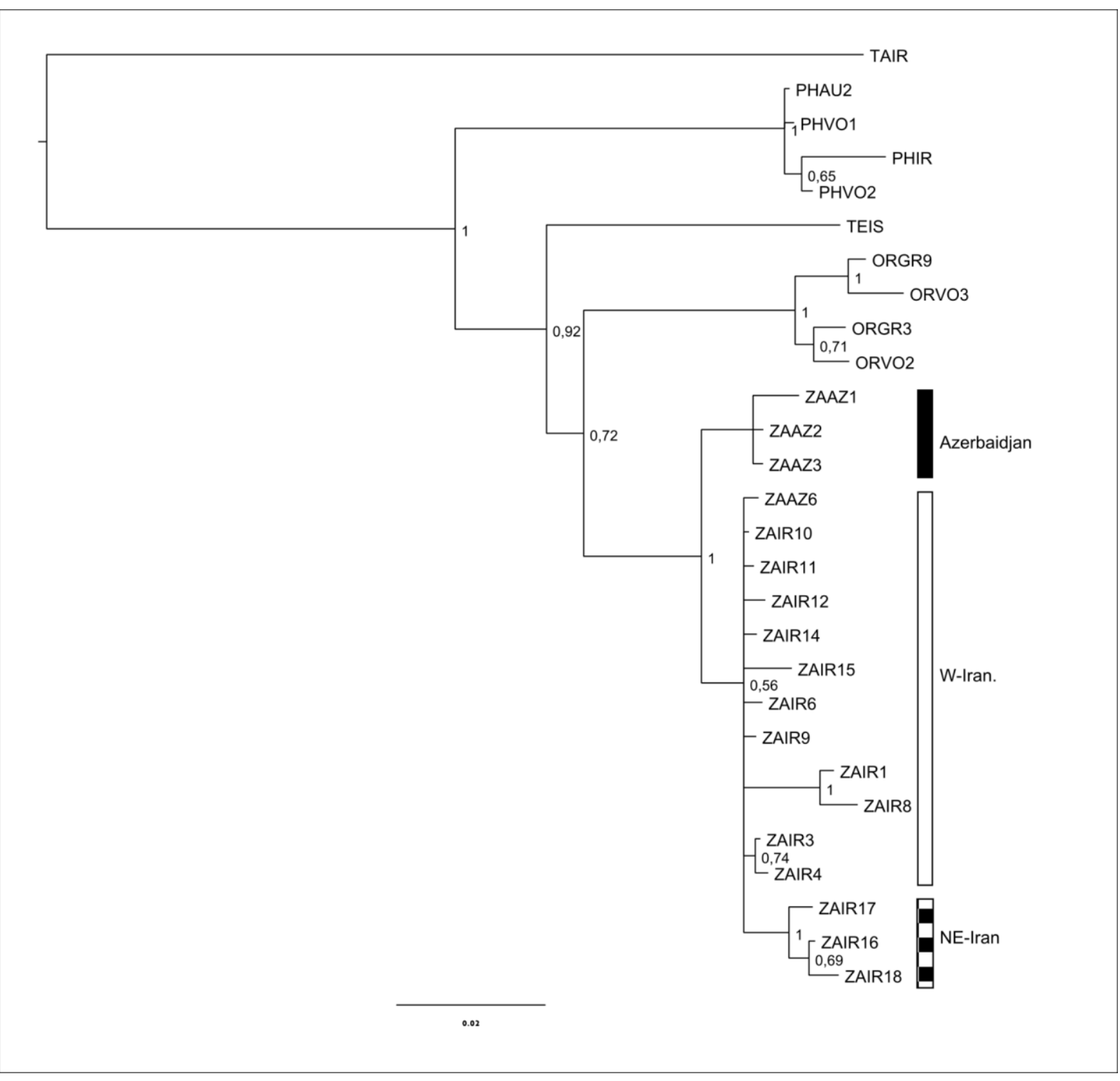

534

535 Fig 2. Consensus phylogeny from the Bayesian inference analysis based on five genes (COI, $536 \quad E F-1, M D H, R p S 5, w g)$. 


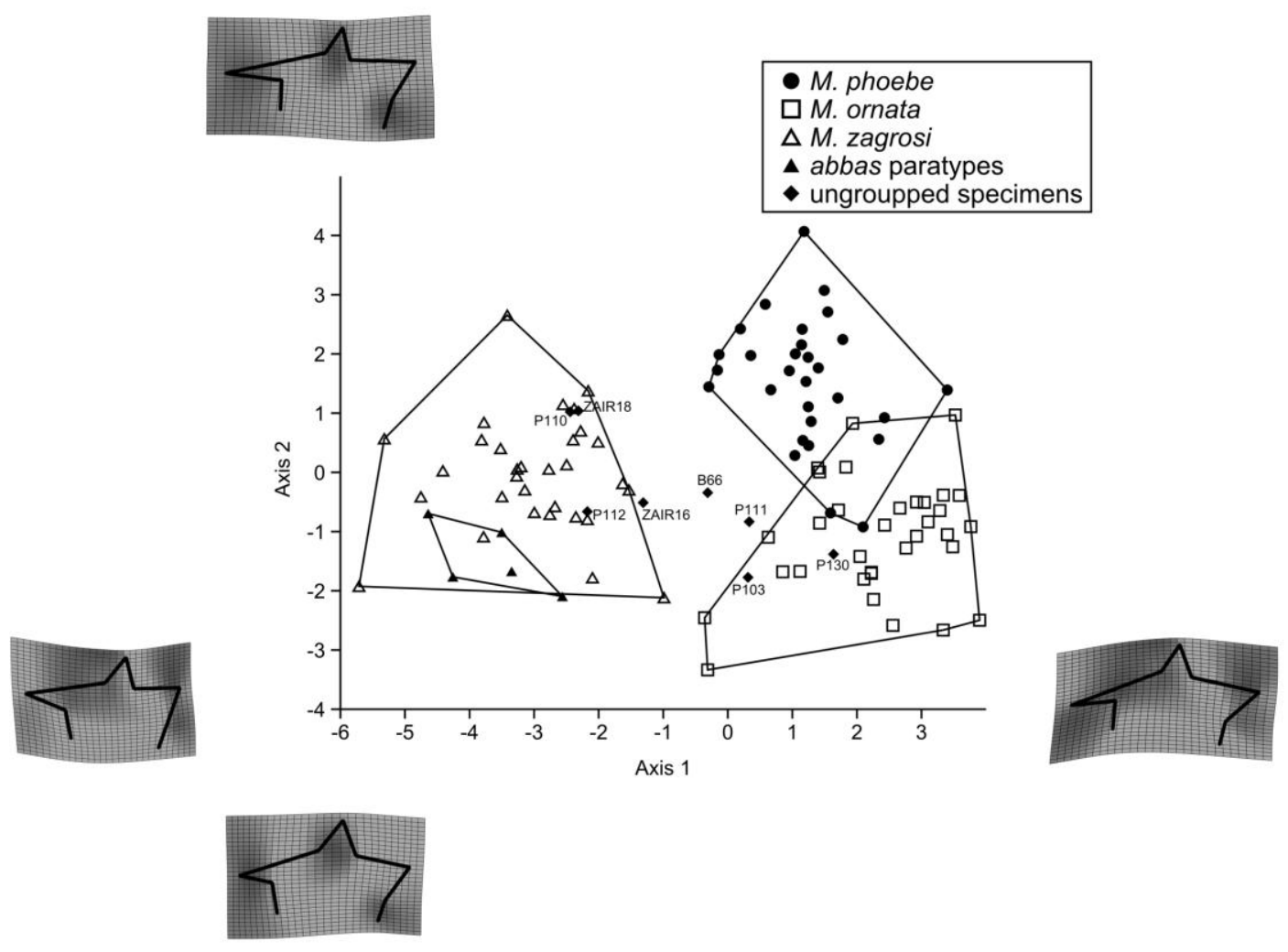

537

538 Fig. 3. CVA scatterplot for the studied taxa. Shape deformations along discriminant axes 539 shown on thin-plate splin. 


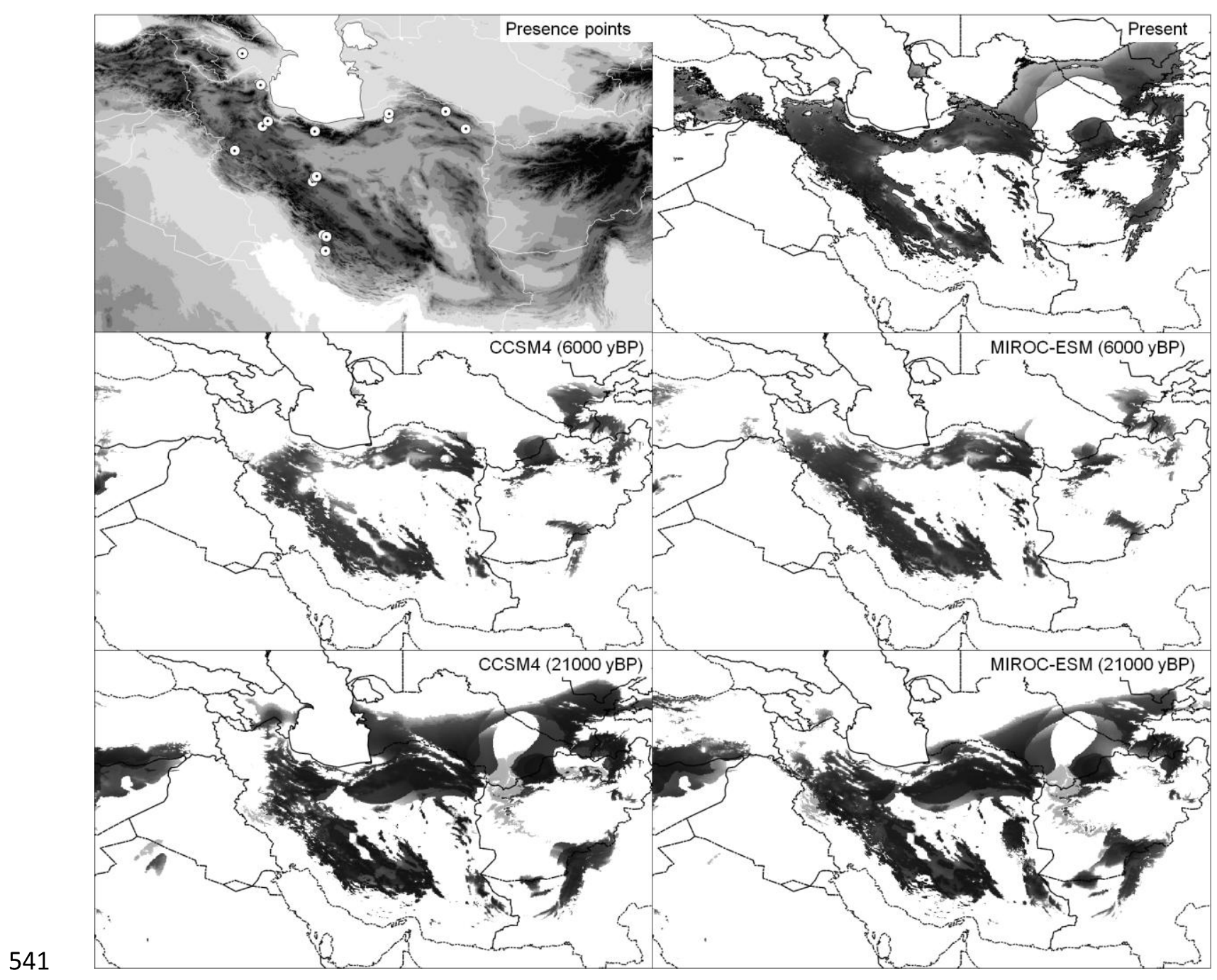

542 Fig. 4. Distribution of Melitaea zagrosi in different time scale. 16 non replicated present 543 points were used to predict the distribution of the species for present climate conditions. 544 Presence points plotted on terrain map. The model was also projected to the Mid-Holocene 545 (6000 yBP) and to the Last Glacial Maximum (21000 yBP) using two global circulation 546 models (CCSM, MIROC). Darker colours show higher climatic suitability for species. 


\section{Supplementary}

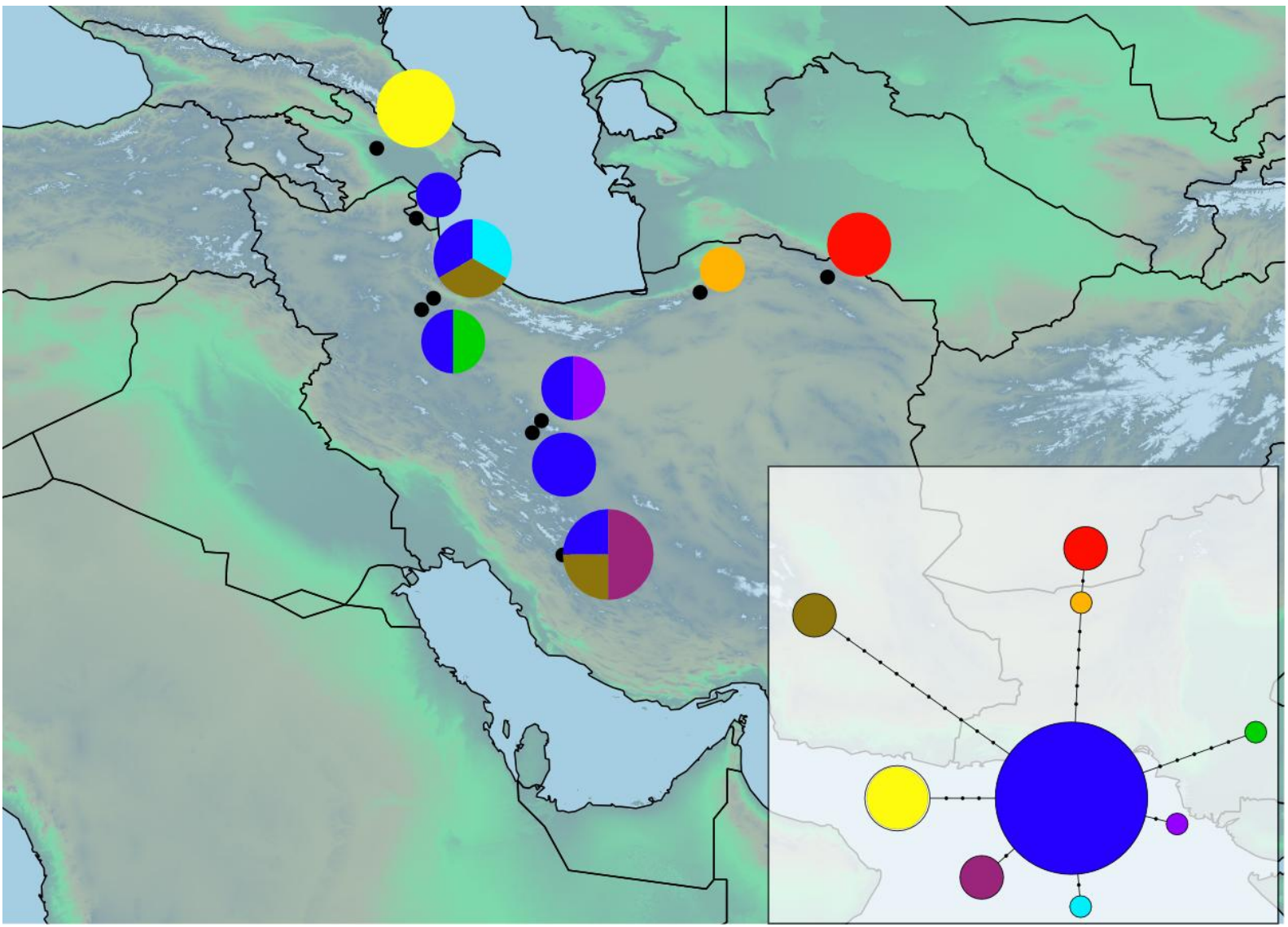

550 Figure S1. Geographical distribution of mitochondrial haplotypes (pie charts) of Melitaea abbas Gross \& Ebert, 1975, comb. n. (= M. zagrosi Tóth \& Varga syn. nova) and haplotype network. 
556 Melitaea specimens used in morphometrical analysis. Abbreviations as follows: 557 HNHM=Hungarian Natural History Museum, Budapest, ZSM=Zoologische Staatssammlung, 558 München, $\mathrm{SMNK}=$ Staatliches Museum für Naturkunde, Karlsruhe, ZMJU= Zoological 559 Museum of the Jagellonian University, Krakow.

\begin{tabular}{|c|c|c|c|c|}
\hline ID & taxa & Country & Location & Museum \\
\hline B072 & ornata & Kazakhstan & Sopka Sauskan-Hg. & HNHM \\
\hline B073 & ornata & Turkey & Angora (Ankara) & HNHM \\
\hline B076 & ornata & Turkey & Angora (Ankara) & HNHM \\
\hline B078 & ornata & Turkey & Ak-Chehir (Aksahir) & HNHM \\
\hline B080 & ornata & Turkey & Angora (Ankara) & HNHM \\
\hline B082 & ornata & Turkey & Angora (Ankara) & HNHM \\
\hline B086 & ornata & Turkey & Amaysia & HNHM \\
\hline B087 & ornata & Turkey & Marasch(Kahranmanmaras), Taurus-Mts. & HNHM \\
\hline B088 & ornata & Turkey & Marasch(Kahranmanmaras), Taurus-Mts. & HNHM \\
\hline B089 & ornata & Turkey & Marasch(Kahranmanmaras), Taurus-Mts. & HNHM \\
\hline B090 & ornata & Turkey & Marasch(Kahranmanmaras), Taurus-Mts. & HNHM \\
\hline N01 & ornata & Russia & Kisilskaja, Ural Mts. & ZSM \\
\hline N02 & ornata & Russia & Kisilskaja, Ural Mts. & ZSM \\
\hline N18 & ornata & Turkey & Egerdir, & ZSM \\
\hline P100 & ornata & Turkey & Egerdir, & ZSM \\
\hline P103 & ornata & Iran & Shahküh Mt., Elburz Mts. & ZSM \\
\hline P111 & ornata & Iran & Mashhad, Kuh-i-Mirabi & ZSM \\
\hline P113 & ornata & Kazakhstan & Djarkent, Ili (region) & ZSM \\
\hline P114 & ornata & Turkey & Marash (Kharamanmaras), Taurus Mt. & ZSM \\
\hline P115 & ornata & Turkey & Bossanti, Taurus Mt. & ZSM \\
\hline P130 & ornata & Turkmenistan & Transcaspian Region, & ZSM \\
\hline P132 & ornata & Russia & Kisilskaja, Ural Mts. & ZSM \\
\hline P173 & ornata & Turkey & Maras, Achyr Dagi, Taurus & ZSM \\
\hline
\end{tabular}




\begin{tabular}{|c|c|c|c|c|}
\hline P184 & ornata & Kazakhstan & Djarkent, Ili (region) & ZSM \\
\hline P23 & ornata & Kazakhstan & Djarkent, Ili (region) & ZSM \\
\hline P32 & ornata & Russia & Kisilskaja, Ural Mts. & ZSM \\
\hline P33 & ornata & Russia & Kisilskaja, Ural Mts. & ZSM \\
\hline P78 & ornata & Kazakhstan & Djarkent, Ili (region) & ZSM \\
\hline P79 & ornata & Kazakhstan & Djarkent, Ili (region) & ZSM \\
\hline P80 & ornata & Kazakhstan & Djarkent, Ili (region) & ZSM \\
\hline P81 & ornata & Kazakhstan & Djarkent, Ili (region) & ZSM \\
\hline P82 & ornata & Russia & Kisilskaja, Ural Mts. & ZSM \\
\hline P85 & ornata & Turkey & Marash (Kahramanmaras), Ahir Dagi, Taurus Mts. & ZSM \\
\hline P86 & ornata & Turkey & Marash (Kahramanmaras), Ahir Dagi, Taurus Mts. & ZSM \\
\hline P87 & ornata & Turkey & Marash (Kahramanmaras), Taurus Mts. & ZSM \\
\hline X34 & ornata & Russia & Ural Mts. & HNHM \\
\hline B100 & phoebe & Russia & Sarepta & HNHM \\
\hline B405 & phoebe & Iran & Askaran, Kordestan province & HNHM \\
\hline B406 & phoebe & Iran & Askaran, Kordestan province & HNHM \\
\hline B407 & phoebe & Iran & $35 \mathrm{Km}$ N from Anarak, Esfahan province, Dasht-e Zir Dom & HNHM \\
\hline B408 & phoebe & Iran & 35Km N from Anarak, Esfahan province, Dasht-e Zir Dom & HNHM \\
\hline B409 & phoebe & Iran & 35Km N from Anarak, Esfahan province, Dasht-e Zir Dom & HNHM \\
\hline B410 & phoebe & Iran & 35Km N from Anarak, Esfahan province, Dasht-e Zir Dom & HNHM \\
\hline B411 & phoebe & Iran & $35 \mathrm{Km}$ N from Anarak, Esfahan province, Dasht-e Zir Dom & HNHM \\
\hline B412 & phoebe & Iran & 35Km N from Anarak, Esfahan province, Dasht-e Zir Dom & HNHM \\
\hline B52 & phoebe & Russia & Sarepta, & HNHM \\
\hline B64 & phoebe & Russia & Koksu, Altai Mts. & HNHM \\
\hline B68 & phoebe & Russia & Kaukazus, & HNHM \\
\hline B69 & phoebe & Russia & Kaukazus, & HNHM \\
\hline B70 & phoebe & Russia & Kaukazus, & HNHM \\
\hline B71 & phoebe & Russia & Kaukazus, & HNHM \\
\hline P136 & phoebe & Russia & Kislovodsk, Kaukasus & ZSM \\
\hline P137 & phoebe & Russia & Kaukasus & ZSM \\
\hline
\end{tabular}




\begin{tabular}{|c|c|c|c|c|}
\hline P148 & phoebe & Russia & Kisilskaja, Ural Mts. & ZSM \\
\hline P15 & phoebe & Russia & Itkol-Hg., Elbrus Mt. & ZSM \\
\hline P150 & phoebe & Russia & Kisilskaja, Ural Mts. & ZSM \\
\hline P152 & phoebe & Russia & Itkol-Hg., Elbrus Mt. & ZSM \\
\hline P17 & phoebe & Russia & Sarepta, & ZSM \\
\hline P19 & phoebe & Russia & Ural Mts. & ZSM \\
\hline P58 & phoebe & Russia & Itkol-Hg., Elbrus Mt. & ZSM \\
\hline P60 & phoebe & Russia & Teberda, Kaukasus & ZSM \\
\hline P62 & phoebe & Russia & Itkol-Hg., Elbrus Mt. & ZSM \\
\hline P64 & phoebe & Russia & Teberda, Kaukasus & ZSM \\
\hline P75 & phoebe & Russia & Sayan Mts., Altai province & ZSM \\
\hline P76 & phoebe & Russia & Anos & ZSM \\
\hline abbas 1 & phoebe abbas & Iran & Fars province, $50 \mathrm{Km}$ NW Ardekan Tange Surkh & SMNK \\
\hline abbas2 & phoebe abbas & Iran & Fars province, $50 \mathrm{Km}$ NW Ardekan Tange Surkh & SMNK \\
\hline abbas3 & phoebe abbas & Iran & Fars province, $50 \mathrm{Km}$ NW Ardekan Tange Surkh & SMNK \\
\hline abbas4 & phoebe abbas & Iran & Fars province, $50 \mathrm{Km}$ NW Ardekan Tange Surkh & SMNK \\
\hline abbas5 & phoebe abbas & Iran & Fars province, $50 \mathrm{Km}$ NW Ardekan Tange Surkh & SMNK \\
\hline B386 & zagrosi & Iran & Esfahan province Kuhha-ye-Qohrud & HNHM \\
\hline B388 & zagrosi & Iran & Askaran, Kordestan province & HNHM \\
\hline B390 & zagrosi & Iran & Askaran, Kordestan province & HNHM \\
\hline B392 & zagrosi & Iran & Askaran, Kordestan province & HNHM \\
\hline B394 & zagrosi & Iran & Zanjan, Zanjan province & HNHM \\
\hline B396 & zagrosi & Iran & Askaran, Kordestan province & HNHM \\
\hline B398 & zagrosi & Iran & Askaran, Kordestan province & HNHM \\
\hline B399 & zagrosi & Iran & Sepidan, Fars province & HNHM \\
\hline B400 & zagrosi & Iran & Sepidan, Fars province & HNHM \\
\hline B401 & zagrosi & Iran & Sepidan, Fars province & HNHM \\
\hline B403 & zagrosi & Iran & Zanjan, Zanjan province & HNHM \\
\hline B404 & zagrosi & Iran & Askaran, Kordestan province & HNHM \\
\hline B66 & zagrosi & Iran & Bognurd (Bojnūrd), Aladag Mt. (Reshteh-ye Ala dagh Mt.) & HNHM \\
\hline
\end{tabular}




\begin{tabular}{|c|c|c|c|c|}
\hline MZAIR10 & zagrosi & Iran & Koshrowabad, Esfahan province & HNHM \\
\hline MZAIR6 & zagrosi & Iran & Koshrowabad, Esfahan province & HNHM \\
\hline MZAIR7 & zagrosi & Iran & Koshrowabad, Esfahan province & HNHM \\
\hline MZAIR8 & zagrosi & Iran & Chatar & HNHM \\
\hline MZAIR9 & zagrosi & Iran & Chatar & HNHM \\
\hline ZAIR16 & zagrosi & Iran & N from Qucan, Kopeth-Dagh 2000m, Khorasan province & ZMJU \\
\hline ZAIR18 & zagrosi & Iran & Khoshyeylaq, Shah kuh $2000 \mathrm{~m}$, Golestan province & ZMJU \\
\hline P106 & zagrosi & Iran & Kazeroun - Buschir, Konar Takhteh & ZSM \\
\hline P108 & zagrosi & Iran & Kazeroun - Shiraz, Mian Kotal & ZSM \\
\hline P109 & zagrosi & Iran & Kazeroun - Shiraz, Mian Kotal & ZSM \\
\hline P110 & zagrosi & Iran & Kandovan, Elburz Mts. & ZSM \\
\hline P112 & zagrosi & Turkmenistan & Transcaspian Region, & ZSM \\
\hline $\mathrm{P} 48$ & zagrosi & Iran & Kazeroun - Buschir, Konar Takhteh & ZSM \\
\hline P50 & zagrosi & Iran & Kazeroun - Shiraz, Mian Kotal & ZSM \\
\hline P51 & zagrosi & Iran & Kazeroun - Buschir, Konar Takhteh & ZSM \\
\hline ZAAZ2 & zagrosi & Azerbaidjan & Akhdash Turyanchay & UD \\
\hline ZAAZ3 & zagrosi & Azerbaidjan & Akhdash Turyanchay & UD \\
\hline ZAAZ5 & zagrosi & Azerbaidjan & Akhdash Turyanchay & UD \\
\hline ZAAZ6 & zagrosi & Azerbaidjan & Akhdash Turyanchay & UD \\
\hline ZAIR10 & zagrosi & Iran & Alazg, Qohrud Mts., Esfahan province & ZMJU \\
\hline ZAIR6 & zagrosi & Iran & Sepidan, Fars province & ZMJU \\
\hline ZAIR7 & zagrosi & Iran & Sepidan, Fars province & ZMJU \\
\hline ZAIR8 & zagrosi & Iran & Sepidan, Fars province & ZMJU \\
\hline ZAIR9 & zagrosi & Iran & Alazg, Qohrud Mts., Esfahan province & ZMJU \\
\hline
\end{tabular}

